\title{
Mean Heart Rate by Electrocardiogram
}

National Cancer Institute

\section{Source}

National Cancer Institute. Mean Heart Rate by Electrocardiogram. NCI Thesaurus. Code C119259.

The calculated average rate of depolarisation of a specific region of the heart, most often the ventricles, as measured and recorded by an electrocardiograph during a specified, extended period of time, and which is usually expressed in beats per minute. 